\title{
Características del proceso fermentativo durante la conservación de aceitunas de la variedad Hojiblanca, destinadas a la elaboración del tipo negras
}

\author{
Por J. Fernández González, A. Garrido Fernández, P. García García, \\ M. Brenes Balbuena y M.C. Durán Quintana \\ Unidad de Biotecnología de Alimentos. Instituto de la Grasa y sus Derivados \\ Avda. Padre García Tejero, 4 - 41012 Sevilla
}

RESUMEN

Caracteristicas del proceso fermentativo durante la conservación de aceitunas de la variedad Hojiblanca, destinadas a la elaboración del tipo negras.

El trabajo estudia la evolución de las caracteristicas físico-químicas y microbiológicas de la fermentación en medio aeróbico durante la conservación de aceitunas de la variedad Hojiblanca, en las diversas condiciones de los actuales procesos industriales $\mathrm{pH}$ corregido inicialmente con acético a 4,0-4,2 unidades, concentración de sal entre 3 y $6 \%$, frutos verdes o con una mayor madurez y aireación a razón de 0,3 litros de aire por hora y litro de capacidad del recipiente).

La misma se caracteriza por un mantenimiento del $\mathrm{pH}$, lenta utilización de los azúcares, bajos niveles de anhidrido carbónico disuelto y progresiva subida de la concentración de sal. Asimismo, se desarrollan bacilos Gram-negativos y Bacillus al comienzo del proceso, pero los microorganismos verdaderamente representativos de la fermentación son las levaduras cuya población aumenta rápidamente (mayor velocidad a medida que la concentración de sal es más baja) y permanecen durante toda la conservación en niveles elevados, si bien, después de 180 dias existe una tendencia general a disminuir Las especies más abundantes son: Pichía membranaefaciens (51\%); Pichía fermentans $(6 \%)$ y Hansenula polimorpha $(6 \%)$. En ningún tratamiento se observa arrugado ni alambrado en las aceitunas.

PALABRAS-CLAVE: Aceituna tipo negra - Fermentación - Levadura.

\section{SUMMARY}

Characteristics of the fermentation process that occurs during the storage in brine of Hojiblanca cultivar, used to elaborate ripe olives.

The paper studies the changes of the physico-chemical and microbiological characteristics of the fermentation in aerobic conditions that occur during the storage stage of Hojiblanca cultivar used to elaborate ripe olives. Assayed treatments include all the conditions used at industrial level (correction of initial $\mathrm{pH}$ to 4,0-4,2 units with acetic acid, sodium chloride concentration ranging between 3 and $6 \%$, green to yellow-pink green fruits and bubling of air at a rate of 0,3 liter per hour and liter of the vessel capacity)

The process was characterized by a maintenance of the $\mathrm{pH}$ values, a slow sugar consumption, very low content of carbon dioxide and progressive increase of the salt concentration. Gram-negative rods and Bacillus grew at the beginning of the process; however, the most representative germs of these fermentation were the yeasts, whose population grew rapidly from brining (at higher rate as the salt content was slower). They remainied throughout the storage, although after 180 days a decrease tendency was observed. The most representative species were: Pichia membranae faciens ( $51 \%$ of frequency). Pichia fermentans $(6 \%)$ and $\mathrm{Han}$ senula polymorpha $(6 \%)$. No gas-pockel or shrivelling was appreciated in any treatment.

KEY-WORDS: Fermentation - Ripe table olive - Yeast

\section{INTRODUCCION}

La elaboración de aceitunas tipo negras, al estilo californiano, ha experimentado en España un notable aumento durante los últimos años produciéndose en estos momentos alrededor de 60.000 Tm./año (C.O.I., 1989).

La mayoría de ellas se obtienen a partir de la variedad Hojiblanca, seguida de la Cacereña. El proceso de oxidación en medio alcalino que requiere esta preparación puede efectuarse directamente en el fruto fresco. Sin embargo, lo normal es conservar las mismas durante un período variable, que, a veces, se puede extender a más de un año. Durante el tiempo que las aceitunas permanecen en salmuera tiene lugar un proceso fermentativo de cuyas características depende, en gran medida, la aparición, o no, de alteraciones, así como la calidad del producto final.

Dado que la fabricación de este tipo comercial se ha iniciado en España en fechas recientes no se conoce bien la forma más adecuada de efectuar dicha conservación de manera óptima, ni la evolución de los diferentes procesos fermentativos que tienen lugar, según las diversas condiciones que se utilizan para la misma.

En California, tampoco se ha realizado un estudio sistemático de esta etapa, ya que los trabajos de Vaughn (1982) se han orientado, fundamentalmente, a investigar las causas de algunas de las frecuentes alteraciones que suelen ocurrir durante ella y, finalmente, hacia el empleo de soluciones fuertemente aciduladas que, en la práctica, inhiben el desarrollo microbiano (Vaughn et al., 1970).

Entre los problemas más importantes que se dan en la variedad Hojiblanca, destacan el arrugado y el "alambrado". La formación del primero se ha deducido que puede deberse a dos causas: utilización de concentraciones iniciales elevadas de sal en la salmuera y la liberación del anhídrido carbónico disuelto en el interior de los frutos, cuando éstos se sacan de los fermentadores.

Por lo que respecta al "alambrado", éste se ha relacionado con la presencia de bacilos Gram-negativos de los géneros Klebsieller, Escherichia y Citrobacter (Gillllard y Vaughn, 1941; Vaughn et al., 1969), y de algunas levaduras fermentativas que se desarrollan en el transcurso de la conservación (Vaughn et al., 1972). En el 
caso de las aceitunas verdes, se ha demostrado también que el crecimiento de bacilos de los géneros anteriormente mencionados, así como de Enterobacter y Aeromonas podían dar lugar a dicha alteración (Rodríguez de la Borbolla et al., 1960). Finalmente, en las aceitunas tipo negras al natural fermentadas anaeróbicamente, se ha quedado claramente establecido que las dos especies de levaduras más representativas, Sacharomyces Oleaginosus y Hansenula anomala, dan lugar asimismo a fisuras similares (Durán Quintana et al, 1979).

Debido a las consideraciones anteriores, el sistema más extendido para conservar las aceitunas tipo negras en España es mediante la utilización de una salmuera con concentración de sal relativamente baja 3-6\% y con el $\mathrm{pH}$ inicial corregido con ácido acético a valores comprendidos entre 4,0 y 4,2 unidades, con objeto de evitar al máximo el desarrollo de bacilos Gram-negativos. Además, se ha extendido el uso del sistema aeróbico, desarrollado inicialmente para evitar el alambrado en las negras al natural, ya que el mismo presenta las ventajas de ir purgando el $\mathrm{CO}_{2}$ a medida que se produce (a partir de la respiración de los frutos y de la propia fermentación), lo que contribuye a disminuir considerablemente el problema de arrugado; al mismo tiempo, el aumento de los niveles de oxígeno disuelto que se provoca en la salmuera inhibe el desarrollo de levaduras fermentativas, estrictamente anaeróbias, responsables del alambrado en negras naturales (García García et al., 1982).

El presente trabajo tiene la finalidad de estudiar la evolución de las principales características físico-químicas del proceso fermentativo que tiene lugar durante la etapa de conservación de aceitunas de la variedad Hojiblanca destinadas a la fabricación de aceitunas tipo negras, así como de investigar los cambios de la población microbiana que se desarrolla y de identificar las especies que la componen.

\section{MATERIALES Y METODOS}

\subsection{Aceitunas}

Los frutos han pertenecido a la variedad Hojiblanca (Olea oleuropaea arolensis), recolectadas en el envero y procedentes de la Roda de Andalucía (Sevilla). Sus principales características han sido descritas por Barranco y Rallo (1984).

\subsection{Fermentadores}

Depósitos de PVC de 100 I de capacidad total, conteniendo $50 \mathrm{~kg}$ de frutos. A los mismos, se les ha dotado de un sistema de aireación mediante columna, acoplada según el procedimiento ya descrito en otro trabajo (Garcia García et al., 1985).

\subsection{Análisis físico-químicos}

El pH se determina potenciométricamente en un aparato Orion modelo 901. Azúcares reductores, cloruro só- dico, acidez total y anhídrido carbónico disuelto según las técnicas descritas por Fernández Díez et al, (1985).

\subsection{Análisis microbiológicos}

Se utilizan diferentes medios para detectar y cuantificar los diversos microorganismos que crecen habitualmente en las salmueras.

Para bacilos Gram-negativos se usa el medio de Mossel (Mossel et al., 1962) (Merck, RFA) y agar nutriente (I.C.M.S.F., 1983). Para microorganismos celulolíticos se utiliza un medio de celulosa-agar (Lamot y Voets, 1976) empleando la solución de Brisou para la observación de la actividad celulolítica de las respectivas colonias (Brisou et al., 1971). Para bacterias lácticas, MRS-agar (Oxoid, Inglaterra) con un $0,2 \%$ de azida sódica con objeto de evitar interferencias debidas al desarrollo de bacilos Gram-negativos y levaduras.

Para el crecimiento de levaduras se usa dextrosaextracto de levadura-agar (González Cancho, 1956) y extracto de malta-agar ( $3 \% \mathrm{p} / \mathrm{v}$ ) (Oxoid, Inglaterra), que permite la diferenciación morfológica de las colonias. Para distinguir las diferentes cepas de levaduras, así como otros microorganismos que pudieran desarrollarse también en estos medios, se efectúa la observación microscópica de cada tipo de colonia.

Para análisis cuantitativos, las siembras de las salmueras se hacen por la técnica de recuento en placa por extensión en superficie (I.C.M.S.F., 1983), preparando disoluciones sucesivas de la muestra para obtener entre 30 y 300 colonias por placa.

\subsection{Identificación de levaduras}

Para el aislamiento de los cultivos puros de levaduras se dan pases sucesivos en el medio agar-extracto de levadura-glucosa por extensión y agotamiento hasta su completa purificación. Posteriormente, se procede a la identificación de los cultivos aislados mediante su estudio taxonómico, siguiendo las normas y técnicas indicadas por Lodder (1970). Los caracteres morfológicos que comprenden las características de la reproducción vegetativa se estudian en extracto de malta líquido. Para la formación de pseudomicelio se emplea agar-patata-glucosa (Wickerham, 1951). La observación de los caracteres de cultivo se realiza tanto en extracto de malta líquido como en agar-infusión de levadura-glucosa.

En las pruebas de esporulación se utiliza el medio de Starkey (1946) y la observación microscópica de las ascosporas se hace según el método de colorantes ácidos con azul de metileno y eosina amarilla (Jorgensen, 1948).

En la utilización fermentativa de los hidratos de carbono se emplean tubos de Durham con un medio basal que contiene $1 \%$ de extracto de levadura. A este medio se le añade el azúcar correspondiente en concentración del $2 \%$ para glucosa, galactosa, maltosa, sacarosa y lactosa y $4 \%$ para rafinosa (Lodder and Kreger Van Rij, 1952).

Para la utilización oxidativa de los hidratos de carbono se emplea el método auxanográfico (Lodder and Kre- 
ger Van Rij, 1952), que consiste en la utilización de un medio basal al cual se le añade, una vez solidificado, los mismos azúcares que se han ensayado en la fermentación.

Además, para completar la taxonomía se ha ensayado también la asimilación, mediante las pruebas API AUX (API SYSTEMS, Francia) los siguientes carbohidratos; celobiosa, trehalosa, xilosa, inositol, glicerol y sorbitol.

En los estudios de utilización de los compuestos nitrogenados se ha empleado igualmente la técnica auxanográfica de Lodder y Kreger Van Rij (1952) probando el $\mathrm{NO}_{3} \mathrm{~K}$ en el medio basal frente a la peptona como testigo.

\subsection{Diseño de la experiencia}

Los diferentes tratamientos experimentados se resumen en la Tabla I. Con ellos se pretenden abarcar todas las posibles variantes que pueden encontrarse en las condiciones reales de trabajo a nivel industrial.

Tabla I

Características de los diversos tratamientos

\begin{tabular}{cccc}
\hline $\begin{array}{c}\text { Código de los } \\
\text { fermentadores }\end{array}$ & $\begin{array}{c}\text { Concentración } \\
\text { inicial de } \mathrm{NaCl}\end{array}$ & $\begin{array}{c}\text { Forma de } \\
\text { adición de } \mathrm{NaCl}\end{array}$ & $\begin{array}{c}\text { Estado de } \\
\text { madurez del fruto }\end{array}$ \\
\hline $\mathrm{L}-1$ & $6 \%$ & $2 \%$ cada mes & verde-maduro \\
$\mathrm{L}-2$ & $6 \%$ & $0,5 \%$ semanal & verde-maduro \\
$\mathrm{L}-3$ & $3 \%$ & $2 \%$ cada mes & verde-maduro \\
$L-4$ & $3 \%$ & $0,5 \%$ semanal & verde-maduro \\
$L-5$ & $6 \%$ & $2 \%$ cada mes & verde \\
$L-6$ & $3 \%$ & $2 \%$ cada mes & verde \\
\hline
\end{tabular}

En todos los supuestos a la salmuera inicial se le corrige el $\mathrm{pH}$ con acético glacial hasta valores de 4,1 unidades y se les inyecta aire durante 8 horas al dia, a razón de 0,3 litros por hora (Ih) y litro de capacidad (IC), durante todo el tiempo que dura el proceso.

Las tomas de muestra se hacen diariamente durante los diez primeros días. Posteriormente, la recogida se realiza semanalmente, para, a partir de los tres meses, hacerlo cada 20-25 días.

\section{RESULTADOS Y DISCUSION}

\subsection{Evolución de las características físico- químicas}

En general, no se han producido diferencias en los valores de la misma debido a las diferentes concentraciones de sal, estados de madurez o forma de adición de sal, por lo que su evolución se estudia en función de los valores medios de los diversos tratamientos.

\section{pH}

Los valores de $\mathrm{pH}$ no han experimentado prácticamente ninguna variación a lo largo de la fermentación manteniéndose en todos los casos entre 4,1 y 4,2 unidades.

\section{Acidez libre}

Como se observa en la Figura 1, a partir de la acidez acética inicial, se observa un ligero incremento de la misma al comienzo del proceso, debido posiblemente a la difusión de los ácidos de la pulpa de los frutos, para estabilizarse a partir de los 30 días de la puesta en salmuera. Así, pues, se ha tratado de una fermentación en medio aeróbico en la que no se ha producido acidez láctica, a causa de la ausencia de crecimiento de bacterias lácticas.

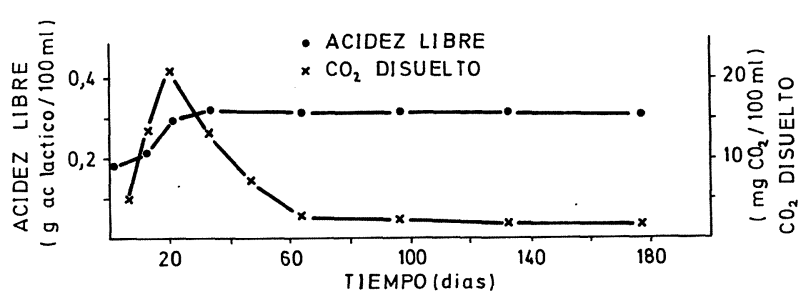

Figura 1

Evolución de la acidez libre y del anhidrido carbónico disuelto en la salmuera

\section{Anhídrido Carbónico disuelto}

La evolución de la concentración del mismo se ha representado en la Figura 1. Desde luego, la aireación ha producido una disminución drástica de los niveles del mismo con respecto al proceso anaeróbio (alrededor de 150-200 mg/100 ml), que explica, en gran parte, la ausencia de arrugado al sacar los frutos de los fermentadores. Al principio de la colocación en salmuera se produce un máximo alrededor de los 7-10 días, a causa de que el caudal de aire empleado no es suficiente para eliminar el $\mathrm{CO}_{2}$ proveniente del propio metabolismo del fruto y de la actividad microbiana. Posteriormente, la cantidad proveniente de las aceitunas va disminuyendo y, paralelamente, lo hacen los niveles de $\mathrm{CO}_{2}$, hasta que se estabiliza en valores muy bajos. Así, pues, se puede afirmar que la proporción de aire utilizada, 0,3 l/lh.lc, durante 8 horas al dia, es suficiente para purgar el anhídrido carbónico de manera eficaz.

\section{Azúcares reductores}

La concentración de estos compuestos en la salmuera ha sido siempre muy baja, debido a que su difusión a la misma es muy lenta y son, en general, utilizados por los microorganismos inmediatamente que alcanzan la solución. Por ello, es más indicativo del grado de avance de la fermentación el seguimiento de la evolución del contenido de los mismos en los frutos, tal como se ha efectuado en la Figura 2. El único efecto que se ha apre- 
ciado ha sido el del grado de madurez, ya que las aceitunas verdes maduras han mantenido a lo largo de la mayor parte de la fermentación unos niveles ligeramente inferiores. Después de los 100 días de estancia en salmuera, esa diferencia desaparece.

Esta lenta eliminación de azúcares reductores hace que el proceso en este tipo de aceitunas se prolongue durante bastante tiempo y el desarrollo microbiano no alcance recuentos tan elevados como en las fermentaciones que tienen lugar en la generalidad de los vegetales $o$, incluso, otros tipos de aceitunas, en los que el equilibrio se alcanza con mayor facilidad (verdes o negras aderezadas en salmuera)

La concentración residual final alrededor de $0,5 \mathrm{~g} / 100$ g de pulpa, no indica la presencia de azúcares libres en la pulpa sino que se puede deber a la presencia de otros compuestos con poder reductor frente al licor de Fehling - a que estos azúcares se mantienen formando compuestos más complejos difícilmente hidrolizables, ya que es normal encontrar valores semejantes en otros tipos de fermentaciones de aceitunas en salmuera (González Cancho et al., 1975).

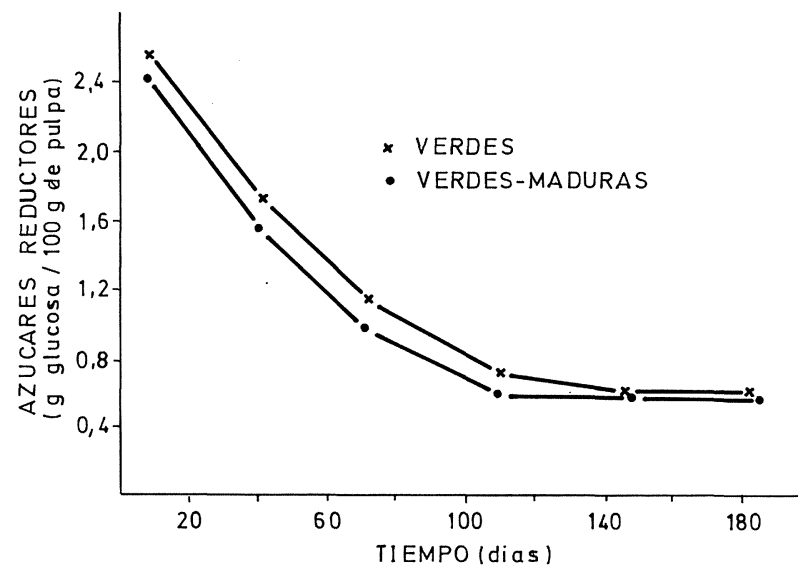

Figura 2

Evolución de los azúcares reductores en la pulpa de las aceitunas según el grado de madurez

\section{Concentración salina}

En la Figura 3 se representan los valores de los análisis y la evolución seguida en las distintas experiencias; las líneas verticales se corresponden con las adiciones de sal que se realizan, según lo programado, semanal o mensualmente.

Cuando se parte de una concentración del 3\% siempre se tienen unos niveles más bajos de sal en el líquido que en los casos del 6\%. Para las mismas condiciones iniciales, la adición semanal implica el mantener en la salmuera una mayor proporción de $\mathrm{NaCl}$ que cuando se realiza mensualmente. No se han encontrado diferencias por el empleo de frutos con distinto grado de madurez.

\subsection{Estudio cuantitativo de la flora microbiana}

Las siembras microbiológicas efectuadas han demostrado que los bacilos Gram-negativos no esporulados prác- ticamente no se han desarrollado en las condiciones de los diferentes tratamientos. Los bacilos del género BaciIlus han tenido una presencia constante, aunque escasa, a lo largo del tiempo de conservación, lo que pudiera indicar la existencia de una contaminación inicial que, gracias al control de las características físico-químicas, no se ha desarrollado. Ello podría, además, justificar el hecho de que, a pesar de haberse detectado estas bacterias de capacidad celulolítica, no se ha observado ablandamiento en los frutos. Dada la escasa significación tanto de los bacilos Gram-negativos, como de los del género Bacillus no se ha profundizado en su estudio.

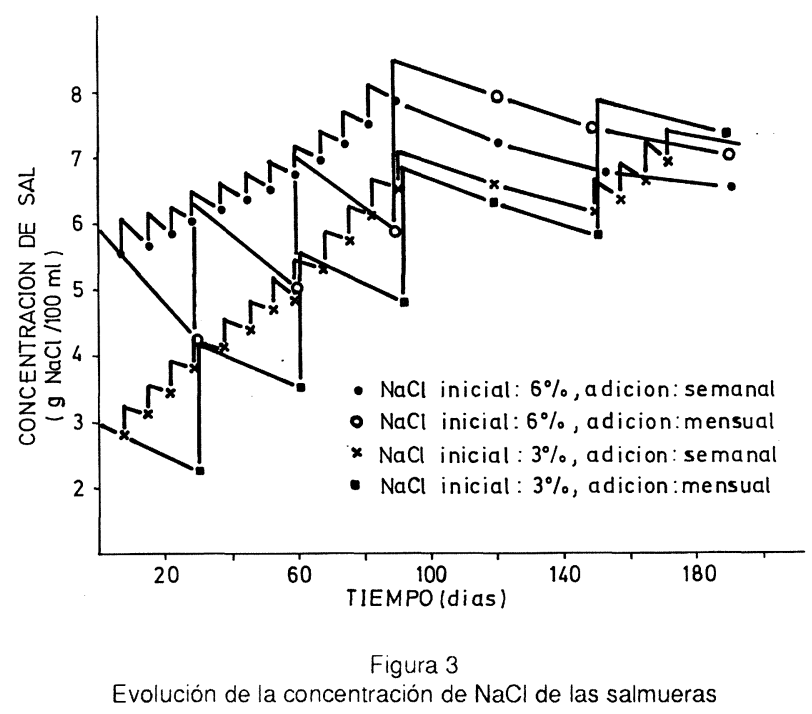

Del resto de los microorganismos, destaca la ausencia total de bacterias lácticas. Este hecho no es extraño si se tiene en cuenta que la presencia de inhibidores en las aceitunas es un hecho demostrado ampliamente (Fleming et al., 1973; Walter et al., 1973; Ruiz Barba et al., 1990 y 1991). Asimismo, la acidulación inicial utilizada para controlar el excesivo desarrollo de bacilos Gramnegativos al inicio del proceso es un factor que puede tener una incidencia negativa en este aspecto, ya que las principales bacterias lácticas que se desarrollan en la fermentación de vegetales muestran una tolerancia limitada a la acidez tanto láctica como acética (McDonald et al., 1990). Finalmente, las concentraciones de sal utilizada no es conocido que ejerzan efecto apreciable sobre dichos gérmenes; sin embargo, el efecto conjunto con el resto de los factores negativos mencionados es posible que tenga alguna influencia que contribuya a la ausencia de las bacterias lácticas en el proceso fermentativo normal seguido actualmente para la conservación de la variedad Hojiblanca.

La inhibición de estas bacterias tiene algunos inconvenientes tales como la débil acidificación del medio que ocurre en estas condiciones y el aumento de la población de levaduras, algunas de las cuales se han relacionado con alteraciones (Durán Quintana et al., 1979 y Garrido Fernández et al., 1979). Por ello, se plantea un importante reto a la investigación: el conseguir un proceso láctico 
con esta variedad, al igual que ya se ha desarrollado en la Gordal (Durán Quintana et al., 1991). Con ello, se podría conseguir el desarrollo de unos microorganismos que se consideran que no tienen efectos negativos sobre los principales atributos de calidad del producto, fundamentalmente la textura (Fernández Díez et al., 1985), así como que su crecimiento genera unas características muy adecuadas para la conservación de los frutos.

Por lo que respecta a las levaduras, éstas han crecido en todos los casos desde el inicio de la colocación en salmuera. Su evolución en los diferentes tratamientos se ha recogido en las Figuras 4, 5 y 6 . En los supuestos en que la concentración inicial de sal es del $6 \%$ (Figura 4) se observa un crecimiento acentuado de la población desde los primeros días hasta llegar a un máximo entre los 80-100 días, a partir de los cuales permanece prácticamente constante durante el resto de la fermentación. Cuando se trabaja con un nivel del 3\% (Figura 5), el crecimiento se prolonga durante más tiempo y el máximo llega posteriormente, entre los 160-180 días. Entonces, se observa un decrecimiento que continúa hasta el final del proceso. Si los frutos tienen un estado de madurez algo menos avanzado (verdes), los cambios que experimenta la población (Figura 6) no se diferencian mucho de los comentados en la figura 5, existiendo también al final una marcada tendencia a descender.

En conjunto, se aprecia una influencia de la forma de adición de la sal y de la concentración inicial, es decir, los niveles de sal afectan al desarrollo de las levaduras, haciendo que el crecimiento de estas disminuya ligeramente cuando la concentración de aquella es mayor. Esta acción puede observarse en las Figuras 4 y 5 , en las que las curvas de los fermentadores con un $0,5 \%$ de adición semanal, están siempre por debajo de las que corresponden al incremento del $2 \%$ para una misma concentración inicial, ya que las primeras mantiene sistemáticamente un porcentaje de sal más elevado en la salmuera. Asimismo, en la Figura 6, la curva de la concentración del $3 \%$ crece más rápidamente al principio manteniendo una ligera tendencia a aumentar hasta, aproximadamen- te, los 160 días en que se alcanza su máximo, momento en que se inicia el descenso. En cambio, con el 6\%, el desarrollo se hace más progresivamente y el máximo se alcanza a los 60-80 días, fechas a partir de las cuales también se aprecia una suave pero constante disminución. El efecto del grado de madurez no ha sido apreciable.

\subsection{Estudio taxonómico de levaduras}

Por todo lo expuesto, las levaduras son los únicos microorganismos verdaderamente responsables de estas fermentaciones, por lo que se ha procedido a la identificación de las especies presentes, ya que sus propiedades y metabolismo influyen decisivamente sobre las características de los frutos conservados y del producto final obtenido en el proceso de oxidación.

En la Tabla II, se expone el número total de cepas aisladas, las especies correspondientes, así como la frecuencia de las mismas, sobre un total de 37 cultivos puros. Se han identificado siete especies distintas, siendo las más representativas: Pichía menbranaefaciens, en primer lugar, que es la más abundante $(51,3 \%)$, seguida de $P$. fermentans y Hansenula polymorpha, ambas con un $16 \%$. Las restantes tienen una escasa significación. En principio, no parece existir diferencias entre las especies más abundantes, debidas a los niveles iniciales de sal.

Las especies más representativas en el proceso anaeróbio de conservación de aceitunas negras al natural en salmuera, eran: Saccharomyces oleaginosus y Hansenula anomala (González Cancho et al., 1975); que, como ya se ha comentado, daban lugar a la alteración denominada "alambrado". Con la introducción del sistema aeróbico se ha evitado, pues, el desarrollo de éstos microorganismos en este tipo de elaboración, al igual que ocurría con los frutos maduros sometidos también al proceso con inyección de aire, en el que la flora encontrada estaba constituida por Torulopsis Candida (19,5\%) Debaryomyces hansenii $(19 \%)$ Hansenula anomala (cuya inci-

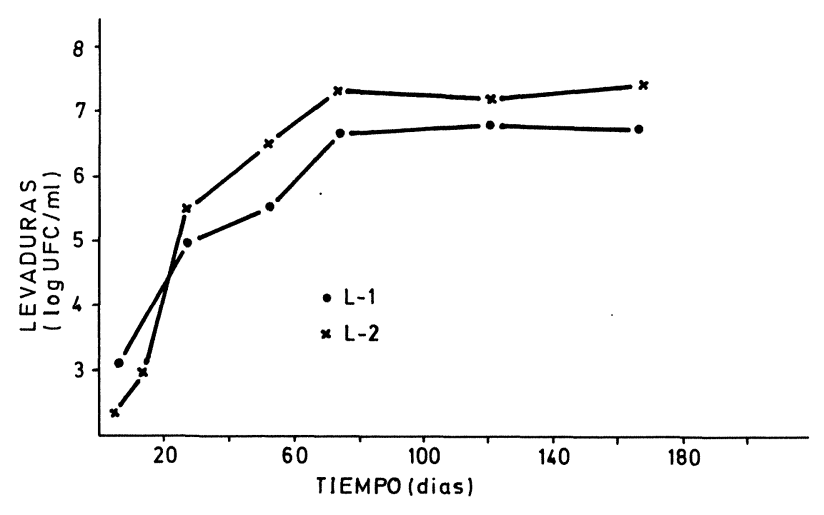

Figura 4

Evolución de la población de levaduras en la fermentación del fruto verde-maduro con una concentración inicial de $\mathrm{NaCl}$ del $6 \%$.

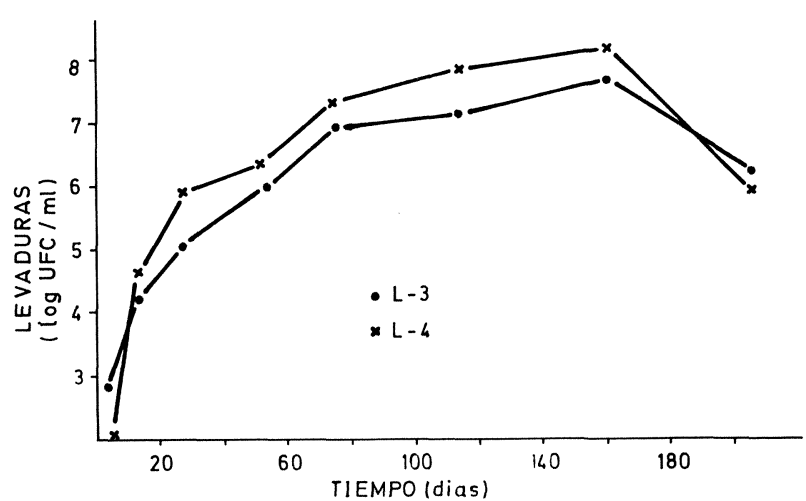

Figura 5

Evolución de la población de levaduras en la fermentación del fruto verde-maduro con una concentración inicial de $\mathrm{NaCl}$ del $3 \%$. 
Tabla II

Especies de levaduras aisladas, número de cepas y sus frecuencias en los diferentes tratamientos.

\begin{tabular}{|c|c|c|c|c|}
\hline \multirow[t]{2}{*}{ Especie } & \multirow[t]{2}{*}{$\begin{array}{l}\text { N.. - de cepas } \\
\text { aisladas }\end{array}$} & \multicolumn{2}{|c|}{$\begin{array}{c}\text { N.. de cepas aisladas } \\
\text { según la concentración } \\
\text { inicial de sal }\end{array}$} & \multirow[t]{2}{*}{$\begin{array}{c}\text { Frecuencia } \\
(\%)\end{array}$} \\
\hline & & $3 \%$ & $6 \%$ & \\
\hline \multicolumn{5}{|l|}{ Pichía mem- } \\
\hline P. fermentans & 6 & 3 & 3 & 16,21 \\
\hline P. etchellsii & 1 & 1 & 0 & 2,70 \\
\hline P. media & 1 & 1 & 0 & 2,70 \\
\hline Hansenula & & & & \\
\hline polymorpha & 6 & 4 & 2 & 16,21 \\
\hline H. dimennae & 3 & 2 & 1 & 8,10 \\
\hline $\begin{array}{l}\text { Scharomyces } \\
\text { oleacens }\end{array}$ & 1 & 0 & 1 & 2,70 \\
\hline Total & 37 & 20 & 17 & 99,97 \\
\hline
\end{tabular}

dencia se habia reducido al $7,8 \%$ ) y Candida didensii $(5,8 \%)$, entre las especies de metabolismo facultativo. Pichia membranaefaciens $(13,6 \%)$, Hansenula mrakii $(10,7 \%)$ y Candida boidinii $(6,8 \%)$, fueron las más destacadas dentro de las de metabolismo oxidativo (García et al., 1985). También, tanto en el sistema anaeróbico como en el aeróbico, se observaba el crecimiento de bacterias lácticas de los géneros Leuconostoc y Pediococcus cuando se trataba de frutos maduros, así como Lactobacillus plantarum, cuando la concentración de sal era inferior al $8 \%$ y, precisamente con la variedad Hojiblanca (Garrido et al., 1990).

Así pues, la principal variación en las especies aisladas con respecto a los demás procesos podría resumirse en que frente al anaeróbio se ha favorecido el crecimiento de levaduras de tipo facultativo u oxidativo, evitando las especies que dan lugar al "alambrado". Además, pa-

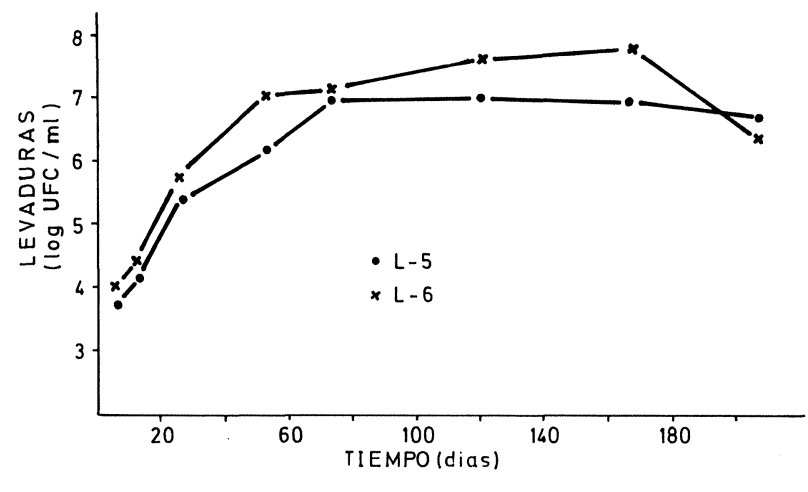

Figura 6

Evolución de la población de levaduras en la fermentación del fruto verde con concentraciones iniciales de $\mathrm{NaCl}$ del 6 y $3 \%$ rece que el grado de madurez ha sido también un factor determinante en el crecimiento de bacterias lácticas. Con el fruto maduro, éstas se desarrollan siempre que los niveles de cloruro sódico no sean inhibidores (menos del $8 \%$ ), mientras que con aceitunas verdes o en el envero, a pesar de mantener unos porcentajes de sal favorables, las bacterias lácticas han estado ausentes. Este comportamiento diferente puede deberse a que en las primeras los niveles de inhibidores sean inferiores, o, a que, debido a su estado de madurez den lugar a una salmuera más rica en factores de crecimiento y en carbohidratos que puedan ser utilizados por las bacterias lácticas.

\section{CONCLUSIONES}

- Las aceitunas verdes o en el envero de la variedad Hojiblanca sufren un proceso fermentativo en medio aeróbico, tanto al $6 \%$ como al $3 \%$ de sal inicial, caracterizado por el desarrollo de levaduras, cuyas especies más representativas son Pichia membranaefaciens, $P$. fermentans y Hansenula polymorpha.

- En el transcurso del mismo, los valores de $\mathrm{pH}$ y acidez se incrementan sólo ligeramente y los azúcares reductores se eliminan muy lentamente, debido a la baja permeabilidad de la piel de estos frutos, con lo que la fermentación se prolonga durante bastante tiempo.

- En cualquier caso, el proceso ha sido satisfactorio para la conservación de estas aceitunas en la etapa previa a su elaboración como tipo negras.

\section{AGRADECIMIENTO}

A la CICYT por la ayuda concedida al proyecto ALI88-0115-CO2-01, dentro del cual se han realizado estas investigaciones, asi como a la firma AGROSEVILLA, S.A., por la cesión de los frutos utilizados.

\section{BIBLIOGRAFIA}

Barranco, D. y Rallo, L. (1984).- "Las variedades del olivo cultivadas en Andalucia".- Ministerio de Agricultura, Pesca y Alimentación. Junta de Andalucia. E.T.S.I.A. Córdoba. España.

C.O.I. (1989).- "Balance de la producción de aceitunas de mesa".- Comité de Expertos del C.O.I. Madrid, noviembre.

Durán Quintana, M.C.; González Cancho, F. y Garrido Fernández, A. (1979).- "Aceitunas negras al natural en salmuera IX. Ensayos de producción del 'alambrado' por incubación de diversos microorganismos aislados de salmuera de fermentación".- Grasas y Aceites 30 361-367.

Durán Quintana, M.C.: Brenes Balbuena, M.; Garcia Garcia, P.; Fernández González, M.J.; Garrido Fernández, A. (1991).- "Estudio comparativo de tres procedimientos para la conservación previa de frutos de la variedad Gordal".- Grasas y Aceites 42, 106-113.

Fernández Diez, M.J.: Castro Ramos, R.: Garrido Fernández, A.; Heredia Moreno, A.; Minguez Mosquera, M.I.; Rejano Navarro L.; Garcia Garcia, P.; Nosti Vega, M. y Castro Gómez Millán, A. (1985).- "Biotecnología de la aceituna de mesa".- Consejo Superior de Investigaciones Cientificas. Madrid-Sevilla, 1985

Fleming, H.P.; Walter jr. W.M. y Etchells, J.L. (1973).- "Antimicrobial properties of oleuropein and products of its hydrolysis from green olives".- Appl. Microbiol. 26, 777-782. 
Garcia Garcia, P.; Durán Quintana, M.C. y Garrido Fernández, A. (1985). "Fermentación aeróbia de aceitunas maduras en salmuera".- Grasas y Aceites 36, 14-20.

Garcia Garcia, P.; Durán Quintana, M.C. y Garrido Fernández, A. (1982)."Modificaciones del proceso de fermentación de aceitunas negras al natural para evitar alteraciones".- Grasas y Aceites 33, 9-17.

Garrido, A.; Durán, M.C.; Garcia, P.; Sánchez, F. and Brenes, M. (1990). "Fermentation of olives in aerobic conditions, 'Processing and Quality of Foods.' Volumen 2: Food Biotechnology: Avenues to healthy and nutritions products".- Proceedings of the Cost 91 bis. Final Seminar. Gotherburg. Sweden. Edited by Zeuten, P.; Cheftel, J.C.; Ericksson, C.; Gormley, T.R.; Linco, P. and Paulus, K.E. Elsevier Applied Science. London, pp. 2-21-2-223.

Gilliland, J. y Vaughn, R.H. (1941).- "Characteristics of coliform bacteria from olives".- J. Bact. 41, 341-354

González Cancho, F. (1956).- "Estudio sobre el aderezo de aceitunas verdes. Población microbiana de las salmueras de aceitunas".- Grasas y Aceites 7, 81-88.

González Cancho, F.; Nosti Vega, M.; Durán Quintana, M.C.; Garrido Fernández, A. y Fernández Diez, M.J. (1975).- "El proceso de fermentación en aceitunas negras maduras en salmuera".- Grasas y Aceites 26, 297-309.

Jorgensen, A. (1948).- "Microorganisms and fermentation".- Charles Griffin and $\mathrm{Co}$. London.

I.C.M.S.F. (1983).- "International Commission on Microbiological Specifjcations for Foods. Microorganismos de alimentos. Volumen 1. Técnicas de análisis microbiológicos".- Editorial Acribia. Zaragoza, España.

Lamot, A. y Voest, M. (1976).- "Cellulolityc activity of aerobic soil actionomycetes".- Z. Allg. Microb. Disch. 5, 16-19

Lodder, J. y Kreger Van Rij, N.J.W. (1952).- "The yeast. A taxonomy study".- North Holland Publishig Co. Amsterdam. London, pp. 2-713.

McDonald, L.C.; Fleming, H.P. y Hassana, H.M. (1990).- "Acid tolerance of Leuconostoc mesenteroids and Lactobacillus plantarum".- Appl. Microbiol. 56, 2.120-2.124.
Mossel, D.A.A.; Mengernink, W.H.J. y Shelts H.H.A. (1962).- "Use of a modified MacConkey agar medium for the selective growth and enumeration of all Enterobacteriaceae".- J. Bact. 84, 381-383.

Rodriguez de la Borbolla y Alcalá, J.M.; Fernández Diez, M.J. y González Cancho, F. (1960).- "Estudio sobre el aderezo de aceitunas verdes XIX. Nuevas experiencias sobre el 'alambrado"'.- Grasas y Aceites 11, 256-260

Ruiz Barba, J.L.; Rios Sánchez, R.M.; Fedriani Irisor, C.; Olias, J.M. y Rios, J.L. (1990).- "Bactericidal effect of phenolic compounds from green olives on Lactobacillus plantarum".- System Appl. Microbiol. 13, 199-205.

Ruiz Barba, J.L.; Garrido Fernández, A. y Jiménez Díaz, R. (1991)."Bactericidal action of oleuropein extracted from green olives against Lactobacillus plantarum". - Letters in Appl. Microbiol. 12, 65-68.

Starkey, R.L. (1946).- "Lipid production by a soil yeast".- J. Bact. 51, 3350

Vaughn, R.M. (1982).- "The fermentation of olives in 'Industrial microbiology"'.- G. Reed Edit., Avi Publi. Co. Inc. Wesport, Conneticut, 4th Ed. pp. 207-236.

Vaughn, R.M.; Stevenson, K.E.; Meyer, M.T. y Patel, I.G. (1970).- "Progress Report on the Year's Research with Olives". 49th.- Technical Report of the California Olive Association. Davis, California. U.S.A.

Vaughn, R.M.: Nasel, C.W.; Levin, R.E.; McMilla, J.D. y York, G.D. (1969)."Gram-negative bacteria associated with sloughing of softening of California ripe olives". J. Food Sci. 34, 224-227.

Vaughn, R.M.; Stevenson, K.E.; Dave, B.A. y Park, H.C. (1972).- "Fermenting yeasts associated with softening and gas pocket formation in olives".- Appl. Microbiol. 16, 1.029-1.035.

Walter jr. W.M.; Fleming, H.P. y Etchells, J.L. (1973).- "Preparation of antimicrobial compounds by Hydrolysis of oleuropein from green olives".- Appl. Microbiol. 26, 773-776.

Wickerham, L.J. (1951).- "Taxonomy of yeasts".- Techn. Bull. n. 1.029 U.S. Dept. Agric. Washington D.C.

(Recibido: Diciembre 1991) 